\title{
Planeación participativa para elaborar un plan de desarrollo municipal: el caso de Acaxochitlán, Hidalgo
}

\section{Participative planning to elaborate a municipal development plan: the case of Acaxochitlán, Hidalgo}

\author{
Aníbal Terrones-Cordero*
}

\begin{abstract}
The objective of this research was to elaborate the Development Plan of the municipality of Acaxochitlan, state of Hidalgo 2009-2015, applying the "ObjectiveOriented Project Planning", participatory workshops were held, and they allowed the diagnosing problems and designing alternative solutions. As a result we have seven development strategic axes: institutional strength, competitiveness and development of the primary activity, suitable road infrastructure and services, generating companies of permanent employments, availability of basic quality public services, honesty and efficiency in the assignment of resources to society, and provision of supports to vulnerable groups. This plan is functional, integral and comprehensive.
\end{abstract}

Keywords: participative planning, regional public policies, plan of municipal development.

\section{Resumen}

El objetivo de esta investigación fue elaborar el Plan de Desarrollo Municipal de Acaxochitlán, Hidalgo 2009-2015, aplicando la Planeación de proyectos orientada a objetivos, para lo cual se realizaron talleres participativos en donde se identificaron el diagnóstico de la problemática y diseño de alternativas de solución, de ello resultaron siete ejes estratégicos: fortaleza institucional, competitividad y desarrollo de la actividad primaria, infraestructura carretera y de servicios adecuados, empresas generadoras de empleos permanentes, disponibilidad de servicios públicos básicos de calidad, honestidad y eficiencia en la asignación de recursos a la sociedad, y provisión de apoyos a grupos vulnerables. Este plan es funcional, integral e incluyente.

Palabras clave: planeación participativa, políticas públicas regionales, plan de desarrollo municipal.

\footnotetext{
*Universidad Autónoma del Estado de Hidalgo, México. Correo-e: aterrones68@hotmail.com
} 


\section{Introducción}

La presente investigación se ubica en el contexto del desarrollo local en el municipio de Acaxochitlán, Hidalgo, el objetivo fue elaborar el Plan Municipal de Desarrollo Económico y Social, 2009-2015 empleando la metodología zopp (por sus siglas en alemán Ziel-Orientierte Projekt-Planung, en español Planeación de Proyectos Orientada a Objetivos) que abajo se describe. Esta estrategia participativa permitió identificar la problemática común de la población de Acaxochitlán y sus posibles soluciones, para ello se realizaron seis talleres participativos en las instalaciones del auditorio municipal. Las estrategias de solución a la problemática vigente se encuentran en los siete ejes rectores formados: fortaleza institucional, competitividad y desarrollo de la actividad primaria, infraestructura carretera y de servicios adecuados, empresas generadoras de empleos permanentes, disponibilidad de servicios públicos básicos de calidad, honestidad y eficiencia en la asignación de recursos a la sociedad y, provisión de apoyos a grupos vulnerables.

Esta investigación está integrada por cuatro apartados: el primero de ellos aborda la importancia que tienen los procesos de participación ciudadana en la planeación para el desarrollo regional, se citan diferentes dependencias y autores que han estudiado esquemas participativos para enfrentar problemas inherentes al desarrollo económico y social en determinadas regiones. En el segundo apartado se describe la metodología zopp, sustento teórico de esta investigación, en él se describe el Árbol de problemas, Árbol de objetivos, Análisis de involucrados, Matriz de planeación del proyecto, Planeación operativa del proyecto y los Talleres de planeación participativa. El tercer capítulo contiene el diagnóstico socioeconómico del municipio de Acaxochitlán; considerando aspectos geográficos y demográficos, haciendo hincapié en la carencia de servicios públicos y la necesidad de elaborar participativamente el plan de desarrollo municipal. El último apartado refiere los siete ejes estratégicos con sus respectivas líneas de acción y proyectos que resultaron de los Talleres de planeación participativa. Finalmente, se presentan las conclusiones derivadas de este análisis.

\section{Esquemas de participación ciudadana para el desarrollo regional y local}

Sociedades democráticas modernas demandan el diseño, implementación y seguimiento de planes, programas o proyectos con el fin de fomentar el desarrollo económico y social en un entorno de igualdad, justicia, sustentabilidad y cuidado al medio ambiente. En la actualidad, la sociedad 
mexicana enfrenta problemas de inseguridad, narcotráfico, secuestro, pobreza, marginación y desempleo, aunado a un deteriorado sistema institucional gubernamental. Ante esta situación los gobiernos federal, estatal y municipal deben coordinarse para diseñar e implementar estrategias de participación ciudadana en los procesos de planeación, ejecución y seguimiento de programas y proyectos a corto, mediano y largo plazo, con la finalidad de mejorar las condiciones de vida de la población.

Históricamente el grado de intervención del Estado en la economía ha sido un tema de debate en cuanto al crecimiento y desarrollo económico. Durante la gran depresión económica de inicios de la década de los treinta, la participación y responsabilidad del Estado en la conducción del desarrollo económico y social fue un elemento clave en la reactivación de la economía. Posterior a este periodo de crisis, en la década de los ochenta, el mercado desempeñó un papel importante en la producción y distribución de los bienes y servicios. Debido a la crisis financiera y económica internacional surgida en Estados Unidos en 2008, hoy por hoy se reconoce que la economía necesita una mayor intervención del Estado para lograr un amplio crecimiento económico, basado en la sustentabilidad del uso y aprovechamiento de los recursos, así como una distribución más equitativa del ingreso y reducción de la pobreza.

El Banco Mundial, en el informe sobre desarrollo mundial, argumentó que el desarrollo exige la existencia de un Estado eficaz que actúe como agente catalizador y promotor, alentando y complementando las actividades de las empresas privadas y de los individuos. El buen gobierno es una necesidad vital, no un lujo, pues sin un Estado eficaz es imposible alcanzar un desarrollo sostenible, tanto en el plano económico como social (Banco Mundial, 1997).

La Comisión Económica para América Latina y el Caribe (CEPAL) sostuvo que no hay modelos universalmente válidos para la política macroeconómica, estrategias para el desarrollo de una competitividad sistémica, conciencia sobre las prioridades ambientales, y políticas intensamente activas en materia social, y agregó que uno de los más serios errores hechos en el último cuarto del siglo xx fue el de promover una solución única en cada una de esas actividades que se apoyaba en el principio de la liberalización plena del mercado. La tendencia a equiparar una integración económica no considera el hecho de que muchas estrategias exitosas no se han apoyado en una apertura total al mercado, más bien, en varios caminos para armar y articular un círculo virtuoso entre el Estado y el mercado (CEPAL, 2002).

Un Estado moderno se justifica en razón de sus fines y el empleo del derecho para conseguirlos. Las responsabilidades genéricas del Estado son: preservar la integridad territorial, defender la soberanía, y garantizar la 
convivencia pacífica estableciendo un orden normativo y vigilando que éste se cumpla. Las funciones sustantivas del Estado son: 1) mejorar la asignación de los recursos, 2) promover el crecimiento económico, 3) hacer más equitativa la distribución del ingreso, 4) procurar el pleno empleo de las personas y la capacidad de producción instalada, 5) buscar la estabilidad de los precios, y 6) garantizar el cumplimiento de la ley: derechos de propiedad, contratos y regulaciones (Musgrave, 1993).

En la democracia social mexicana, la responsabilidad central del Estado es proporcionar la satisfacción de las necesidades básicas de la población, y liberar a cada habitante de los obstáculos que le impiden, en su calidad de ser humano libre, su desarrollo como persona digna. La constitución faculta al Estado para intervenir y dirigir el desarrollo nacional, entendido como proceso de cambio que combine el crecimiento económico con la justicia social. En la constitución se define a la democracia "no solamente como una estructura jurídica y un régimen político, sino como un sistema de vida fundado en el constante mejoramiento económico, social y cultural del pueblo" (Tello, 2007).

Ante la premisa de que el desarrollo económico nacional se fundamenta en las estrategias locales, los gobiernos municipales constituyen un sistema fundamental para alcanzar el desarrollo regional y, con ello, nacional.

El término de ciudadanía ha sido discutido ampliamente por Alicia Iriarte et al. (2003), así como Manuel Pérez (2000), quienes lo consideran como la capacidad de construir espacios e intereses comunes en un entorno de libertad, participación, independencia, autonomía, igualdad, solidaridad y diálogo dentro de un Estado-nación. En esta vertiente, el Programa de las Naciones Unidas para el Desarrollo (PNUD) establece que "la ciudadanía no puede ser definida sólo por el derecho al voto" sino que deben considerarse el carácter igualitario, fundamentado en el reconocimiento universal de los derechos y obligaciones de todos los miembros de una sociedad democráticamente organizada (PNUD, 2004).

El crecimiento y desarrollo económico de una sociedad implica necesariamente procesos continuos de cambios estructurales en el ámbito productivo, político y social de las diferentes regiones de un determinado país. Estos procesos tienen éxito cuando se construyen de abajo hacia arriba; es decir, se debe partir de un diagnóstico participativo de los recursos humanos, naturales y materiales que prevalecen en una determinada región con el fin de diseñar e implementar estrategias de desarrollo de acuerdo a las necesidades de la sociedad (Pardo, 1994; Sánchez et al., 2003; Silva, 2003).

Los gobiernos locales y sus comunidades deben orientar sus propios recursos para crear los vínculos adecuados con el sector privado, con el fin de generar empleos y estimular la actividad económica en una zona 
definida. La identificación de las necesidades y potencialidades de las comunidades se debe realizar de manera participativa (Blakely y Green, 2010).

Existe una marcada relación y mutua interdependencia entre la región y los actores sociales, éstos desempeñan un rol importante en el desarrollo económico y social de una determinada región, puesto que ayudan a entender a la gente que la habita, sus necesidades, su historia, su problemática y sus posibles soluciones (Giménez, 1994; Terrones y Sánchez, 2010).

Una región es una construcción sociocultural en la cual el territorio se va conformando a partir de la dinámica de los procesos sociales que tienen como base una multitud de ámbitos locales y comunitarios, mismos que se van articulando por la lucha de los actores a través de las dinámicas económicas, culturales, históricas y sociales que les lleva a modelar la región como un ámbito territorial extendido (Giménez, 1996; Canabal, 2001). Desde el punto de vista de Adán Guillermo Ramírez (2004), la región es un espacio geográfico donde se realizan actividades productivas con presencia de actores sociales y políticos que promueven el crecimiento económico. Por su parte, Romero Conturruero (1998) es partidario del enfoque territorial para el desarrollo, él considera a la región como el entorno desde donde los actores pueden desarrollar ventajas en el contexto de la globalización, referidos a la competitividad y la cooperación para atraer al territorio inversiones y recursos.

Desde la perspectiva de esta investigación, se considera a la región como un espacio físico delimitado por una superficie, constituido por elementos naturales (fauna, flora, precipitación pluvial, clima, hidrología, suelo, etc.) y, la presencia de un conjunto de habitantes que interactúan con la naturaleza desarrollando un conjunto de actividades a efecto de satisfacer sus necesidades biológicas, sociales y culturales, dentro de un marco institucional (Terrones y Sánchez, 2010).

Ramírez (2004) elaboró una guía metodológica para la formulación y evaluación de proyectos de educación ambiental bajo un esquema participativo, donde plantea la necesidad de realizar, en consenso, una planeación de los proyectos con el fin de priorizar actividades, definir fechas, responsables de la ejecución y monitoreo de las diferentes actividades.

Asimismo, Frans Geilfus (2000) estableció cuatro tipos de herramientas en el proceso participativo que deben considerarse según las necesidades y realidades de la comunidad, y de la institución de desarrollo, éstas son: técnicas de dinámica de grupos, visualización, entrevistas y comunicación oral, así cómo observación de campo. La técnica de grupo es fundamental para trabajar con varias personas y lograr su participación 
efectiva. Las técnicas de visualización ${ }^{1}$ son representaciones gráficas donde se logra la participación de personas con diferentes grados y tipos de educación y se facilita la sistematización de conocimientos.

Morales (1998) concluyó que el desarrollo local se da mediante la identificación de las potencialidades productivas de la comunidad y determinación de las diferentes causas que generan el problema central, esto con el fin de buscar alternativas de solución a dicha problemática y, con ello, mejorar las condiciones de bienestar de la población, en un marco participativo.

En el ámbito rural, por ejemplo, el desarrollo del sector agrícola de los países subdesarrollados implica la identificación y priorización de los proyectos productivos que deben llevarse a cabo en un marco participativo en donde intervengan los propios productores y las dependencias públicas encargadas de apoyar el desarrollo rural (Farrington, 1989). La FAO (1990), al aplicar técnicas grupales en la explotación forestal, obtuvo un incremento en la producción de madera con un uso sustentable del bosque en regiones de Brasil y Colombia, esto ocasionó la eliminación de conflictos entre los beneficiarios del recurso y un aumento de los ingresos derivados de esta actividad. Por su parte, Leurs (1996) planteó la necesidad de planear de manera permanente el desarrollo rural en un marco participativo. El compromiso de las dependencias gubernamentales y demás involucrados es llevar a cabo lo acordado en los Talleres de planeación participativa, pues sólo de esta manera se logra el desarrollo económico y social de los habitantes del medio rural.

Así, la participación ciudadana es uno de los elementos que contribuye a fomentar la democracia, que es importante traducir en proyectos específicos en donde los ciudadanos contribuyan activamente en la toma de decisiones de manera colegiada (Osorio, 2009). Las decisiones públicas se ven limitadas si no se consideran las prioridades señaladas por los mismos ciudadanos (Olvera, 1999). Schönhuth (1994) desarrolló y analizó lineamientos generales de planeación participativa en el medio rural, concluyó que la planeación es eficiente siempre y cuando participen activamente todos los involucrados, tanto en la identificación de necesi-

\footnotetext{
${ }^{1}$ Representan: a) matrices, cuadros que permiten ordenar y presentar las informaciones e ideas en forma lógica, con el fin de cruzar diferentes criterios (matrices de clasificación y de priorización) o de presentar ideas en forma jerárquica (matrices de planificación y otras), sus aplicaciones son prácticamente ilimitadas; b) mapas, representaciones simplificadas de la realidad que tienen aplicaciones en las fases de diagnóstico y análisis, muchas veces sirven de punto de partida para los procesos de desarrollo; c) flujogramas, un tipo de diagramas que se presenta en forma esquemática, las relaciones entre diferentes elementos (simbolizados por flechas) como relaciones de causa a efecto y secuencia de eventos, así también, d) diagramas temporales, representaciones de la presencia/ausencia o de la variación en intensidad de ciertos fenómenos en el tiempo.
} 
dades y prioridades comunes, así como en la elaboración, ejecución y seguimiento de alternativas de solución plasmadas en proyectos.

\section{Planeación de proyectos orientada a objetivos}

La planeación participativa, como forma de proyectar el desarrollo, toma en cuenta las opiniones de los diferentes involucrados en talleres de trabajo participativo. Las condiciones de desarrollo actuales demandan planes, programas y proyectos con un enfoque participativo, puesto que mediante la aplicación de esta metodología se identifican prioridades comunitarias y se diseñan las estrategias y acciones adecuadas para impulsar el desarrollo integral. Para obtener resultados favorables, la planeación debe partir del conocimiento pleno de la realidad y del contacto permanente con la población (Forster y Osterhaus, 1995).

La participación ciudadana en los procesos de planeación cobra importancia debido a la ineficiencia y falta de representatividad del sistema de planeación tradicional, que se caracteriza por diseñar, ejecutar y dar seguimiento a lineamientos establecidos de manera unilateral (de arriba hacia abajo), con resultados que no se reflejan en un mejoramiento de las condiciones de vida de la población. Ante esta problemática, es cada vez más necesario establecer un sistema de planeación de abajo hacia arriba donde se consideren las diferentes opiniones de todos los agentes involucrados en el diagnóstico, diseño, ejecución y seguimiento de proyectos específicos (Terrones y Sánchez, 2010).

Para la elaboración del Plan de Desarrollo Municipal de Acaxochitlán se usó el método zopp (por sus siglas en alemán Ziel-Orientierte ProjektPlanung, en español: Planeación de Proyectos Orientada a Objetivos), la aplicación de esta metodología permitió identificar, con la participación de los comisariados ejidales, delegados municipales, representantes de colonias, instituciones gubernamentales (de carácter federal, estatal y municipal), de enseñanza e investigación, organizaciones sociales y políticas, así como de la población en general, las necesidades principales de la población del municipio de Acaxochitlán, así como las causas y efectos que vinculan las acciones de gobierno y sociedad con el desarrollo económico y social de dicho municipio.

En 1981, la Agencia Alemana de Cooperación Técnica: Team Technologies (GTZ), aplicó el zopp en la planeación de proyectos, este enfoque se difundió por todo el mundo: lo han adoptado, entre otros organismos internacionales, la Organización Internacional del Trabajo (оIт), el Programa de las Naciones Unidas para el Desarrollo (PNUD), la Organización Mundial de la Salud (oms), la Organización Panamericana de la Salud (ops), la Organización de las Naciones Unidas para la Agricultura y la 
Alimentación (FAO), el Banco Interamericano de Desarrollo (BID) y el Banco Mundial (GTZ, 1995).

En el caso de México, el zopp lo ha llevado a cabo la Comisión $\mathrm{Na}$ cional del Agua (CNA, hoy Conagua) en la elaboración de planes integrales del uso y manejo de aguas en los diferentes acuíferos del país y, que han servido como base para la elaboración de la ley de aguas nacionales. También, gobiernos municipales lo han aplicado en la elaboración de los planes de desarrollo, con colaboración de instituciones de enseñanza e investigación (Terrones y Sánchez, 2010).

El zopp es aplicable a todo tipo de proyectos, independientemente de si la organización contraparte es un organismo estatal, un banco, una asociación u otra organización no gubernamental, y de si el grupo destinatario está constituido por los habitantes de un poblado o por empresas del sector privado. La experiencia demuestra que los proyectos sólo tienen éxito cuando se basan en el esfuerzo de los grupos destinatarios. Los aspectos a considerar en el zopp son: Árbol de problemas, Árbol de objetivos, Análisis de involucrados, Matriz de planeación del proyecto y Planeación operativa del proyecto; estos instrumentos de análisis implican la realización de Talleres participativos, que los llamaremos talleres zopp.

\subsection{Arbol de problemas}

El Árbol de problemas es el diagnóstico de la situación, se realiza a partir de la identificación del problema central y la visualización y análisis de las causas y efectos que originan dichos problemas. En general, un problema se expresa en términos de la falta de determinados medios que podrían servir para resolverlo: falta de crédito, inadecuado uso del agua, ausencia de regulaciones legales, falta asistencia técnica, escasa coordinación interinstitucional, etc. Los planificadores tienen que aplicar métodos que partan de la visión de los afectados y comparen entre sí las distintas perspectivas.

Los proyectos se diseñan porque existe un problema de desarrollo, o bien, un obstáculo para lograr el desarrollo, mismo que se genera porque existe un servicio público deficiente, o simplemente, no existe. Muchas veces hay consenso de que la situación actual es insatisfactoria, que se requiere un cambio, por lo que a esa situación insatisfactoria se le denomina situación actual, de tal forma que si existe una situación actual insatisfactoria se deduce que existe también una situación futura deseada que sería el resultado de una intervención diseñada para mejorar algunos o todos los elementos de la situación actual. Esa intervención es un proyecto o un programa que se ejecuta en el corto y mediano plazo para 
lograr, en el mediano y largo plazo, la situación deseada (Osterhaus y Salzer, 1995).

Se debe tomar en cuenta que el Árbol de problemas no pondera las causas de acuerdo con su contribución a producir el efecto; un Árbol de problemas puede tener iteraciones o círculos que complican el análisis, es decir, causas iguales que se presentan en distintas secciones del árbol, incluso en niveles y jerarquías diferentes.

No existe un número máximo o mínimo de problemas, se trata de incluir todas las contrariedades importantes percibidas por los involucrados, para poder entender las relaciones de causalidad (causa-efecto) y así obtener un diagnóstico lo más objetivo posible. Además, es relevante llegar a los obstáculos que constituyen las raíces principales del problema de desarrollo, ya que las soluciones de dichos problemas tienden a mejorar la viabilidad de una eventual estrategia del proyecto.

\section{2. Árbol de objetivos}

El planteamiento de un objetivo pretende modificar y mejorar a futuro una situación actual, es lo que se quiere alcanzar. Los responsables políticos de un proyecto estarán dispuestos a aceptar y asumir una modificación justificada de los objetivos del proyecto, siempre que resulte claro cuál es el sentido de dicha modificación, y que los beneficios que representa compensen los costos que pueda ocasionar. Los objetivos deben ser factibles, considerando los recursos disponibles dentro de las condiciones generales dadas.

El Árbol de objetivos es un instrumento para la toma de decisiones, por ello también se le llama Árbol de decisiones, éste describe la situación deseada a la que se quiere llegar mediante la solución de los problemas, transformando las relaciones causa-efecto en relaciones medios-fines.

El Árbol de objetivos se forma convirtiendo el problema, que está en el nivel más alto del Árbol de problemas, en un objetivo. Luego se sigue trabajando hacia abajo, convirtiendo cada causa en un medio para abordar el problema de desarrollo, formulando cada condición negativa como una condición positiva, es decir, objetivos que son deseados y factibles en la realidad. Es mejor identificar primero los fines y luego los medios para alcanzar o propiciar esos fines.

Se puede prescindir de algunos objetivos no factibles y agregar otros más específicos que contribuyan al fin. La dificultad de formular un objetivo quizá se deba a una deficiencia en el planteamiento del problema; en este caso, se puede y se debe corregir el elemento del Árbol de problemas que crea la dificultad. Al final, se revisa el Árbol de objetivos de 
abajo hacia arriba, asegurando que las relaciones causa-efecto del Árbol de problemas se han convertido en relaciones medio-fin.

\subsection{Análisis de involucrados}

El Análisis de involucrados se centra en los principales actores. En un proyecto pueden estar involucradas muchas dependencias gubernamentales y no gubernamentales, públicas o del sector privado, organizaciones de base o de apoyo, de producción y de servicios; cada una tiene sus propios objetivos e intereses, su propia cultura organizacional, ya que con frecuencia no es fácil armonizar los distintos intereses.

Se identifican todas las personas, grupos y organizaciones involucradas directa e indirectamente con el proyecto, indicando sus funciones, intereses, fortalezas y debilidades. Se examina la realidad social y las relaciones de poder. Los planificadores tendrán que distinguir entre los involucrados activos (líderes) y pasivos (con poca o nula participación presencial, porque ha sido delegada a sus representantes).

\subsection{Matriz de planeación del proyecto}

La Matriz de planeación del proyecto (MPP) sirve para informar a las instancias que asumen la responsabilidad del proyecto. La presentación de información en esta matriz puede realizarse también fuera del proceso participativo de planificación, si al hacerlo no se modifica unilateralmente lo acordado. Una MPp está expuesta al cambio, cuanto más profundo el nivel de planificación, tanto más frecuentemente se requieren modificaciones. La MPP expresa, de manera integrada, la estrategia de ejecución del proyecto, misma que comprende la definición del objetivo superior, objetivo del proyecto y las actividades, así como sus indicadores verificables objetivamente y supuestos.

\subsubsection{Objetivos superiores: de desarrollo y del proyecto}

En el contexto de la planeación de proyectos existen las siguientes categorías de objetivos: a) objetivo superior, b) objetivo de desarrollo, y c) objetivo del proyecto. El objetivo superior hace énfasis en lograr el aspecto global de la problemática planteada; mientras que el objetivo de desarrollo concentra la atención de todos los actores involucrados en el proyecto, en el proceso de desarrollo de los grupos destinatarios. Los proyectos se llevan a cabo para fomentar procesos de cambio que repercuten siempre en determinadas personas y organizaciones. La función del objetivo de desarrollo es dar una perspectiva conjunta al proceso de cambio que se pretende 
impulsar. El objetivo del proyecto describe el cambio que se desea introducir en la actuación de personas u organizaciones.

La contribución del proyecto está orientada a lograr que se produzca dicho cambio. A través de ella los grupos destinatarios estarán en condiciones de mejorar su situación. También se puede describir el objetivo del proyecto como un hito en el camino hacia el objetivo de desarrollo. Para lograr el objetivo del proyecto es necesario que las personas y organizaciones destinatarias del cambio participen activamente.

\subsubsection{Actividades}

Las Actividades son los pasos que conducen a la obtención de un resultado, para determinarlas se recomienda saber en qué etapa de la planificación nos encontramos. En la planificación general de un proyecto nuevo o de una nueva fase de un proyecto en curso no tiene sentido anticipar con lujo de detalles, ya que con seguridad habrá que descartar gran parte de lo planteado. De hecho, las cosas evolucionan a menudo de una manera completamente diferente de como se pensó.

La gerencia del proyecto debe asegurar que se lleven a cabo las Actividades para asegurar el éxito de las metas. Es necesario tener una lista detallada de las Actividades ya que serán la base para la elaboración de la Planeación operativa del proyecto. Se coloca cada Actividad requerida para un componente en orden cronológico y se estima el tiempo y recursos requeridos para realizarla.

\subsubsection{Indicadores verificables objetivamente}

Los indicadores están relacionados con los objetivos, resultados y supuestos del proyecto. Permiten formarse una idea sobre el nivel de exigencias y los criterios de éxito del proyecto, sirven a la gerencia del proyecto como hilo conductor en sus Actividades de seguimiento y evaluación. Los indicadores son el resultado de un proceso de consenso y reflejan el parecer conjunto de todos los involucrados. Si no se han definido indicadores precisos, esto, en general, tiene repercusiones negativas en la ejecución, dando lugar a malentendidos y conflictos, debido a que los involucrados interpretan de manera diferente el nivel de exigencias o el alcance de los objetivos a los que se aspira. Los indicadores pueden referirse a productos físicos (por ejemplo, aumento de la productividad del trabajo) o a cambios en la organización (por ejemplo, mayor coordinación interinstitucional).

Los Indicadores verificables objetivamente incluyen las metas a ser alcanzadas. Es la especificación cuantitativa o cualitativa utilizada para 
medir el logro de un objetivo. Debe ser aceptada colectivamente por los involucrados como adecuada para medir los logros del proyecto.

\subsubsection{Supuestos}

Se llaman Supuestos a los factores externos que tienen que estar dados para que un proyecto tenga sentido y sea realista. Por ejemplo, el Banco Central asesora a bancos pequeños en el establecimiento de relaciones de crédito comercial con microempresas. El objetivo del proyecto es: Las microempresas solicitan y reciben créditos en las condiciones habituales del mercado. Un supuesto podría ser que existe organización en la gestión de crédito por parte de las microempresas.

Existen situaciones que están fuera del control de la gerencia o entidad ejecutora del proyecto y que suponen riesgos para éste, es decir, es posible que aun cumpliendo con las actividades, por ejemplo, no se puede cumplir con producir resultados (productos) si estos riesgos ocurren. Los riesgos pueden ser financieros, sociales, políticos, ambientales, institucionales climatológicos, etc., y pueden llevar a que el proyecto fracase. El riesgo se expresa, convencionalmente, como un supuesto que debe ocurrir.

Los Supuestos son muy importantes tanto en el diseño como en la ejecución; en el diseño ayudan a identificar riesgos que pueden ser evitados o mitigados, incluyendo Actividades y hasta componentes, en la ejecución del proyecto. Por ejemplo, uno de los Supuestos de un proyecto de cultura del agua es que instituciones educativas estén dispuestas a difundir información sobre el uso adecuado del agua. Dado que este supuesto es de vital importancia para el logro del propósito, no debiera dejarse al azar la voluntad del sector educación de difundir la información. El equipo de diseño del proyecto debería incluir en el proyecto Actividades que promuevan que personal calificado informe a la población estudiantil. Estas Actividades podrían consistir en incluir en el programa educativo un sistema de cuidado del recurso agua. Un proyecto bien diseñado es aquel cuyos riesgos son manejables, pues mientras más cercana sea la probabilidad estadística de ocurrencia de los Supuestos, mayor será la probabilidad de que el proyecto produzca sus Actividades y logre su fin.

\subsection{Planeación operativa de proyecto}

Contiene una desagregación de las Actividades principales contenidas en la MPP en subactividades, con una asignación de atributos que permiten hacer administrables o monitoreables las Actividades, como resultados esperados, fechas de ejecución, responsables y supuestos. 


\subsubsection{Subactividades}

Para obtener los resultados de un proyecto, en ocasiones, es necesario establecer las Subactividades que implican una determinada acción específica dentro de una Actividad, esto con el fin de que el planteamiento considerado en ésta se cumpla de manera completa, permitiendo esclarecer los medios en el logro del objetivo del proyecto. El éxito de la planeación participativa radica en llevar a cabo las Subactividades de manera adecuada.

\subsubsection{Resultados}

Los Resultados son los productos y servicios que aportan las organizaciones que ejecutan el proyecto para que puedan producirse los cambios esperados en los receptores de la contribución (Objetivo del proyecto). Son las obras, estudios, servicios, capacitación, etc., que debe producir el proyecto con el presupuesto asignado. Cada componente debe ser necesario para lograr el propósito y debe ser razonable suponer que si todos los componentes son producidos de la manera planeada se cumplirá el propósito.

\subsubsection{Medios de verificación}

Los Medios de verificación describen las fuentes de información necesarias para la recopilación de los datos que permiten el cálculo de los indicadores. Por lo tanto, éstos constituyen la base del sistema de monitoreo del proyecto. Por lo general, el sistema de monitoreo y evaluación describe los niveles, personas, eventos, procedimientos, documentos y datos que deben ser usados para realizar el seguimiento de la ejecución del proyecto.

Un buen Indicador debe ser verificable por algún medio, por tanto, el valor de un Indicador se limita o amplía por los medios que se dispongan para verificarlo. Si se requiere una encuesta amplia para obtener los datos necesarios para verificar el Indicador y el proyecto no tiene fondos para pagar la encuesta, entonces debiera buscarse otro Indicador. La verificación de algunos indicadores podría requerir, simplemente, de una rápida revisión de registros en oficinas públicas (fuentes secundarias de información), mientras que otros requieren para su verificación de la recolección y análisis sofisticados de datos (fuentes primarias de información).

\subsubsection{Responsables y fechas de ejecución}

La Planeación operativa del proyecto especifica detalladamente la contribución que deben prestar los diversos actores, y pone en claro las respec- 
tivas responsabilidades. Es importante que el o los responsables de llevar a cabo la ejecución y seguimiento de los proyectos cumplan cabalmente con los lineamientos establecidos de forma conjunta y, sobre todo, informen periódicamente sobre los avances, problemática y resultados obtenidos. La Planeación operativa del proyecto también establece las fechas de ejecución de las diferentes Actividades con el fin de cumplir en tiempo y forma los objetivos de los proyectos considerados.

\subsection{Talleres ZOPP}

Si los afectados son involucrados y ellos se encargan de mejorar sus condiciones de vida, se logra un éxito desde el punto de vista del desarrollo. Cada etapa de planificación dependerá del asunto en cuestión considerando a quién se da participación y en qué forma. La Planeación participativa, como comúnmente se la ha denominado al zopp, sirve para desarrollar la concepción del proyecto a partir del punto de vista de los afectados.

Para que el proyecto tenga éxito, quien asume responsabilidad debe participar en las decisiones, aunque participar no significa necesariamente decidir, a veces sólo se trata de informar y consultar. Para que pueda participar en la planificación el mayor número posible de personas y organizaciones afectadas se requieren tiempo y métodos adecuados. La planificación desde abajo, con una amplia participación, cuesta un gran esfuerzo.

Los planificadores deben decidir, a partir de la situación dada, en qué medida es necesario y posible planificar desde abajo para asegurar que el punto de vista de los grupos destinatarios, sobre su proceso de desarrollo, sea adecuadamente incorporado a la planificación. Es necesario involucrar actores que estén realmente legitimados por los grupos destinatarios. Los planificadores deben investigar, con sentido crítico, quién tiene el mandato de hablar en nombre de los grupos destinatarios y en qué se basa ese mandato.

Los talleres son instrumentos de la gestión de proyectos con una finalidad determinada. Se pueden realizar talleres para transmitir información y conocimientos, mejorar las relaciones de trabajo entre los miembros del equipo, y apoyar funciones de gestión, tales como planificación y evaluación. Los talleres complementan otros tipos de actividad, tales como reuniones o trabajo de escritorio, pero no lo reemplazan. Son uno de los elementos del proceso, y no el proceso en sí.

De acuerdo a la temática del taller se decide a quién se invita, cuánto tiempo se le dedica y qué etapas de trabajo se planifican. Todos los aspectos organizativos de un taller deben decidirse de acuerdo a los objetivos 
que se plantean: lugar de reunión, alimentación, alojamiento, elementos para facilitar que los miembros estén relajados y motivados, moderación, idioma de la discusión, distribución de los lugares, visualización, etcétera.

En los talleres se logra un consenso en la forma de considerar la situación, ponen de manifiesto las diferencias entre distintos intereses y puntos de vista. Además, han demostrado ser eficaces para aclarar una situación de necesidad y estrategias de solución directamente con los afectados.

El uso de técnicas de visualización, por ejemplo, tarjetas de colores y carteleras, ha demostrado ser eficaz. La visualización eleva las probabilidades de que se preste atención a opiniones y puntos de vista de los participantes que, de otro modo, no se habrían manifestado. La moderación, visualización, trabajo en grupos y filmación en video son algunos métodos apropiados para los talleres de planeación.

El tiempo necesario para la realización de los Talleres de planeación participativa depende de, entre otros factores, la problemática a tratar, la dinámica de trabajo, la logística (lugar de realización de los talleres, disponibilidad de los participantes), cobertura de la planeación y apoyos económicos. En general, el tiempo promedio para la realización de los Talleres de planeación participativa es de 30 a 48 horas (GTZ, 1995).

\section{Diagnóstico socioeconómico del municipio de Acaxochitlán}

El municipio de Acaxochitlán cuenta con una superficie de $226.10 \mathrm{~km}^{2}$, lo que representa $1.08 \%$ de la superficie total del estado, se encuentra a $69 \mathrm{~km}$ de distancia de la capital, sus coordenadas geográficas son: $20^{\circ} 10^{\prime}$ latitud norte y $98^{\circ} 12^{\prime}$ latitud oeste. Tiene una altura de 2,260 msnm. Colinda al norte y este con el estado de Puebla; al sur con el estado de Puebla y el municipio de Cuautepec de Hinojosa; al oeste con los municipios de Tulancingo de Bravo y Metepec (INEGI, 2000a).

Acaxochitlán está integrado por 36 comunidades (PMA, 2006). Cuenta con 40,583 habitantes (INEGI, 2010). La población trabajadora ha mostrado un incremento y una transición de su vocación productiva, pasando de ser mayoritariamente agrícola al sector terciario. En el año 2000, el mercado laboral registró una Población Económicamente Activa (PEA) ocupada de 10,503 donde $30.2 \%$ pertenecen al sector primario, $25.7 \%$ al secundario y $44.1 \%$ al sector terciario (INEGI, 2000b).

En 2010 existían 22,313 personas derechohabientes y 17,954 no derechohabientes. Del personal derechohabiente, 931 estaban afiliadas al Instituto Mexicano del Seguro Social (IMSs), 355 al Instituto de Seguridad y Servicios Sociales de los Trabajadores del Estado (ISSSTE), y el resto al Seguro Popular (INEGI, 2010). 
El municipio de Acaxochitlán contaba, en el 2010, con 8,238 viviendas particulares ocupadas. De estas 1,155 tienen piso de tierra mientras que 7,083 viviendas el piso es diferente al suelo. Las viviendas con agua entubada fueron 4,839, es decir, 3,399 viviendas carecen de agua entubada, lo que representa $41.26 \%$ de las viviendas totales, principalmente aquellas construidas en el ámbito rural (zona alta), así como en asentamientos irregulares. Cabe señalar que una correcta administración del servicio de agua potable depende de múltiples factores, entre los que destacan: la capacitación del personal, la detección de usuario y tomas clandestinas, la actualización del padrón de usuarios y la promoción de una cultura del agua. De las viviendas ocupadas, $43.36 \%$ no disponen de drenaje y $7.40 \%$ no cuentan con el servicio de energía eléctrica (INEGI, 2010). Ante la problemática de acceso total a los servicios públicos básicos y a la carencia de empleos en la región de Acaxochitlán, aunado a la falta de un Plan de Desarrollo Municipal Integral, es importante el diseño y ejecución de un esquema de desarrollo con visión de corto, mediano y largo plazo con participación de todos los agentes involucrados.

\section{Resultados de la aplicación de la metodología zopp en el municipio de Acaxochitlán}

El objetivo de esta investigación fue elaborar el Plan de Desarrollo Económico y Social del municipio de Acaxochitlán, Hidalgo, para el periodo 2009-2015, con la colaboración de autoridades del H. Ayuntamiento municipal, comisariados ejidales, delegados municipales, líderes políticos y sociales, empresarios, organizaciones comerciales y civiles, dependencias estatales y federales y, sociedad en general. Este plan considera estrategias de desarrollo de corto, mediano y largo plazo y tiene como finalidad mejorar las condiciones económicas y sociales de la población del área de estudio.

La Constitución Política de los Estados Unidos Mexicanos (CPEum), en su artículo 26, establece el sistema nacional de planeación, teniendo como eje central el Plan Nacional de Desarrollo, considerado como marco de referencia en la elaboración de este estudio. En el Artículo 115 de la CPEUM se reconoce la personalidad jurídica del municipio para ejercer la facultad reglamentaria del Ayuntamiento, además de que le otorga sustento legal para establecer convenios de coordinación con el Estado para la prestación de los servicios públicos y la ejecución de obras públicas, formular los planes de desarrollo urbano, reservas territoriales y ecología y, considera la participación municipal en los fenómenos de conurbación. Le transfiere, además, jerarquía constitucional para el manejo planificado de su patrimonio y la libre administración de la hacien- 
da municipal (CPEum, 2002). Se han considerado los planteamientos del Plan Estatal de Desarrollo 2005-2011 del Gobierno de Hidalgo (GEH, 2005). También se tomó en cuenta, como documento esencial, el Plan Municipal de Desarrollo de Acaxochitlán, Hidalgo 2006-2009, elaborado por el presidente municipal constitucional (PMA, 2006).

Atendiendo al objetivo de la presente investigación, se realizaron un total de seis talleres zopp, los días 27, 29 y 31 de octubre de 2008, y 10, 12 y 14 de noviembre de 2008 en el auditorio de la presidencia municipal de Acaxochitlán, con una duración total de 36 horas, fungiendo como moderador y responsable de impartir los talleres zopp el autor de este trabajo.

El día 27 de octubre de 2008 en las instalaciones de la presidencia municipal de Acaxochitlán se llevó a cabo la primera reunión formal de trabajo sobre la metodología zopp con el fin de elaborar el Árbol de problemas: estuvieron presentes 36 personas, entre los que se encontraban autoridades y delegados municipales, comisariados ejidales, representantes de colonias, productores agropecuarios, jornaleros, amas de casa, discapacitados, estudiantes, desempleados, migrantes, profesionistas y comerciantes. Entre las dependencias participantes, asistieron representantes de la Universidad Autónoma del Estado de Hidalgo; la Secretaría de Salud; la Secretaría de Desarrollo Social (Sedesol); la Secretaría de Desarrollo Económico del Estado de Hidalgo; Secretaría de Agricultura, Ganadería, Desarrollo Rural, Pesca y Alimentación (Sagarpa); y la Secretaría de Educación Pública (SEP) de Hidalgo.

Para poder llevar a cabo el taller zopp, el moderador puso énfasis en realizar participativamente los cinco instrumentos considerados por la metodología zopp: Árbol de problemas, Árbol de objetivos, Análisis de involucrados, Matriz de planeación del proyecto y Planeación operativa del proyecto, para ello describió detalladamente cada uno de estos instrumentos. Para formar el Árbol de problemas, el moderador pidió a los participantes que escribieran en tarjetas de trabajo, problemas comunes actuales en sus comunidades y colonias. En la discusión de los problemas planteados, las necesidades más importantes en la actualidad son: la falta de empleos; abandono de la actividad agropecuaria; falta de financiamiento al campo; problemas de acceso a la salud y educación (básica, media superior y superior) de calidad; lentitud y carencia en la provisión de los servicios públicos, tales como luz eléctrica, agua potable, drenaje, seguridad, recreación, deporte, pavimentación y transporte.

El día 29 de octubre de 2008 se realizó el segundo taller zopp, al que asistieron 37 personas. En este contexto, los delegados municipales y comisariados ejidales mencionaron que los caminos y carreteras de acceso a sus comunidades requieren ampliación, nivelación, revestimiento y pavi- 
mentación, pues en tiempo de lluvias se dificulta el acceso y en algunos periodos se imposibilita transitar con vehículo. Con relación a los discapacitados, afirman que existen, en promedio, diez discapacitados en cada una de las comunidades del municipio que no cuentan con recursos propios ni apoyos gubernamentales para sus cuidados básicos (salud y alimentación). Por su parte, los adultos mayores indicaron, que debido a su edad, ya no están en condiciones de trabajar y obtener una fuente de ingresos para su manutención; careciendo, además, de pensión y servicios de salud. Los representantes de colonias de Acaxochitlán argumentaron que aún existen algunas viviendas que no cuentan con drenaje, agua potable, luz eléctrica y pavimentación. Así también manifestaron que el robo a casa habitación y el problema de vandalismo en los jóvenes es cada vez más frecuente, fenómeno que se extiende hacia las comunidades cercanas a la cabecera municipal. Los productores agrícolas comentaron que no cuentan con apoyos para incentivar la producción, careciendo de financiamiento y asesoría técnica para aumentar los rendimientos de los cultivos, aunado a los altos costos de los insumos y bajos precios del producto.

El 31 de octubre de 2008 se realizó el tercer taller zopp, estuvieron presentes 36 personas, entre ellos jóvenes egresados de escuelas de nivel superior, quienes argumentaron que la falta de oportunidades de empleo impiden que se circunscriban al campo laboral, aunado a la grave situación de pobreza y marginación en la región, de tal manera que las familias salen a buscar mejores oportunidades de empleo al interior del país, pero la emigración más importante es hacia Estados Unidos. Los habitantes de las comunidades apelan por una mayor y eficaz atención a sus demandas por parte de las autoridades municipales, ya que tienen que ir varias veces a la presidencia municipal para que se solucione una demanda ciudadana; también argumentaron que no están informados sobre las acciones del gobierno municipal en cuanto a la gestión de los recursos públicos, pues sostienen que, por su situación de pobreza y marginación, no se enteran de los apoyos municipales, estatales y federales, por lo que demandan información oficial. Todos estos datos fueron la base para formar el Árbol de problemas, identificándose como problemas centrales el desempleo y la falta de servicios públicos básicos (figura I).

El 10 de noviembre de 2008, con una asistencia de 37 personas, se llevó a cabo la cuarta sesión del taller zopp; al inicio del taller el moderador explicó a los participantes la importancia de tener identificada con claridad la problemática del municipio (Árbol de problemas). Enfatizó que la elaboración del Árbol de objetivos consistía en expresar la condición a la que se desea llegar mediante la solución de problemas, es decir, transformar los problemas en soluciones. Así, se inició con la elaboración del Árbol de objetivos (figura II), éste fue concluido en la quinta sesión 


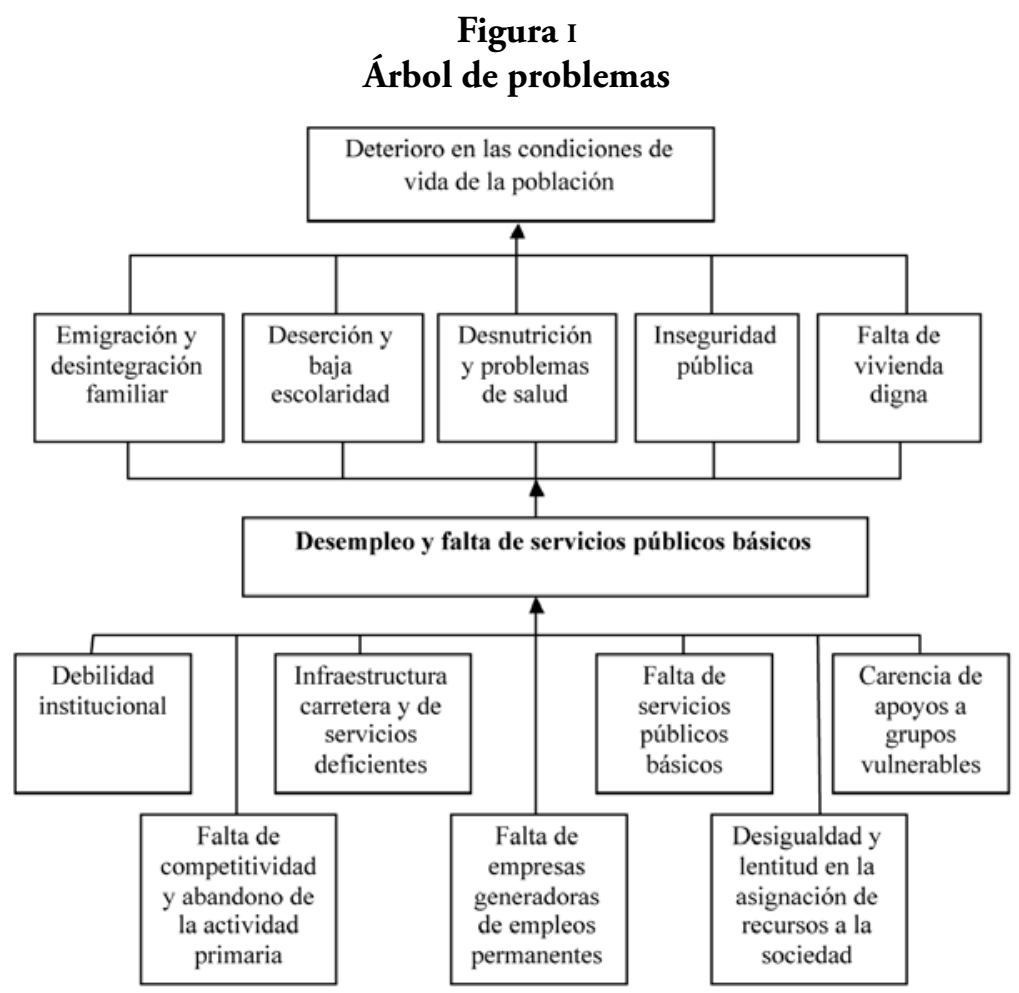

Fuente: Elaboración propia con información generada en los talleres zopp.

del zopp, realizada el 12 de noviembre de 2008 donde asistieron 37 personas. Del Árbol de objetivos se obtuvieron los ejes rectores, líneas de acción, proyectos y actividades que forman la base del Plan Municipal de Acaxochitlán (figura II).

Los ejes estratégicos brindan direccionalidad a las líneas de acción y, a la vez, cada una de estas líneas de acción comprende proyectos orientados a dar solución a una problemática particular mediante la implementación de Actividades. Estos ejes son: fortaleza institucional, competitividad y desarrollo de la actividad primaria, infraestructura carretera y de servicios adecuados, empresas generadoras de empleos permanentes, disponibilidad de servicios públicos básicos de calidad, honestidad y eficiencia en la asignación de recursos a la sociedad y, provisión de apoyos a grupos vulnerables. Estos ejes se describen a continuación:

\section{Fortaleza institucional}

Este eje estratégico tiene como objetivo fortalecer la estructura institucional ya que un sistema institucional fuerte permite al gobierno cumplir con la tutela, de manera efectiva, de los derechos de la sociedad. Para 


\section{Figura II}

\section{Árbol de objetivos}

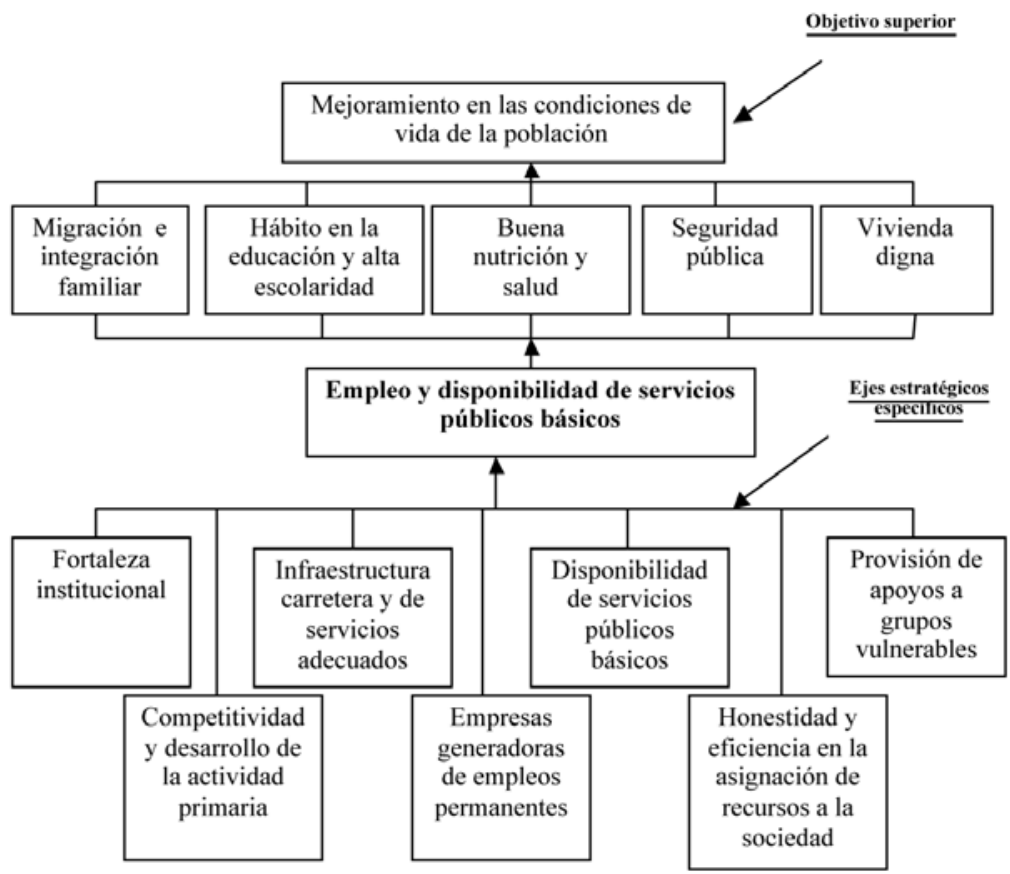

Fuente: Elaboración propia con información generada en los talleres zopp.

cumplir con este objetivo se definen seis líneas de acción: eficiente coordinación institucional, impartición de justicia y seguridad en casa habitación y calles, seguridad en las escuelas, protección de los derechos humanos de la población, desarrollo integral de la familia, y eficiente recaudación de impuestos. Estas líneas de acción, junto con los proyectos se presentan enseguida:

EFICIENTE COORDINACIÓN INSTITUCIONAL

\section{Claridad sobre la responsabilidad social}

Alta participación e integración social

IMPARTICIÓN DE JUSTICIA Y SEGURIDAD EN CASA HABITACIÓN Y CALLES Impartición de justicia y seguridad pública en las comunidades y colonias

Fomento a la vida sin drogas

Seguridad en las ESCUELAS

Regulación en la venta de alcohol alrededor de las escuelas

Fijación de señalamientos viales alrededor de las escuelas Implementación de vigilancia en las escuelas 
PRoteCCión DE LOS DERECHOS HUMANOS DE LA POBLACIÓN

\section{Atención a los derechos humanos de la población en general}

Cuidado de los derechos humanos de adultos mayores, indígenas y discapacitados

DesarRollo integral DE LA FAMILIA

Atención a nińos de la calle

Prevención y atención al maltrato familiar

Prevención y tratamiento del alcoholismo

EFICIENTE RECAUDACIÓN DE IMPUESTOS

Instrumento recaudatorio eficiente

\section{Competitividad y desarrollo de la actividad primaria}

Es necesaria la inversión pública y privada en el desarrollo del sector primario de Acaxochitlán, por lo que el gobierno debe fomentar la ganadería, agricultura, silvicultura y acuacultura, con el fin de crear fuentes de empleos en la región y, con ello, crear las condiciones de estabilidad en el desarrollo municipal, evitando la emigración laboral y desintegración familiar.

En el gobierno municipal debe ser prioritario generar las condiciones para el desarrollo y fortalecimiento de las empresas, así como promover la capacitación laboral para la incorporación al aparato productivo de mano de obra calificada que favorezca el incremento de la calidad, la productividad y la competitividad de trabajadores y empresas.

El objetivo de este eje estratégico es desarrollar la actividad primaria eficientemente. Para el cumplimento de este objetivo general se establecieron cuatro líneas de acción: apoyo adecuado a la producción agrícola y pecuaria, uso sustentable del recurso forestal y aprovechamiento óptimo de la acuacultura. Estas líneas de acción junto con los proyectos se presentan enseguida:

Apoyo ADECUAdo A LA PRODUCCIÓN AGRíCOLA

\section{Métodos de riego óptimos en la agricultura}

Apoyos institucionales suficientes para desarrollar la agricultura APOYO ADECUADO A LA PRODUCCIÓN PECUARIA

Mejoramiento de la infraestructura en la producción pecuaria

Mejoramiento genético

Apoyos institucionales adecuados en la producción pecuaria

Uso Sustentable Del ReCURso forestal

Promoción de una cultura racional en el uso forestal

Capacitación en la explotación forestal Prevención y control de incendios forestales 
Aprovechamiento óptimo de la ACUACUltura

Promoción y capacitación en la producción de peces

Financiamiento en la adquisición de organismos producidos

\section{Infraestructura carretera y de servicios adecuados}

Las vías de comunicación acercan a los pueblos, previenen la delincuencia, fomentan la inversión productiva y, en general, impulsan el desarrollo económico regional. El objetivo general de este eje estratégico es proveer de una infraestructura carretera de calidad a la región para impulsar el desarrollo del municipio de Acaxochitlán. De acuerdo con la problemática de infraestructura carretera presente en la región, diagnosticada en los Talleres de planeación participativa, se definieron cinco líneas de acción: caminos de acceso a las comunidades suficientes, mejoramiento en los caminos de terracería, mantenimiento continúo en carreteras pavimentadas, aumento de carreteras de calidad y fijación de señalamientos viales. Estas líneas de acción junto con los proyectos se presentan enseguida:

CAMinOS DE ACCESO A LAS COMUNIDADES SUFiCIENTES

Ampliación de caminos de acceso

Conclusión de caminos de acceso

Mejoramiento en los Caminos de terRacería

Mantenimiento eficaz en carreteras de terracería

Disponibilidad de maquinaria

Adecuada planeación en el diseño de carreteras

MANTENIMIENTO CONTINÚo EN CARRETERAS PAVIMENTADAS

Cambio de carpetas asfálticas en mal estado

Mantenimiento antes y después del periodo de lluvias

Aumento de Carreteras de Calidad

Diseńo y construcción de carreteras de cuatro carriles

FiJACión de SEÑALAMIENTOS VIALES

Colocación de seńalamientos viales en los accesos a las comunidades

Colocación de señalamientos en escuelas

\section{Empresas generadoras de empleos permanentes}

La poca actividad industrial en el municipio contribuye a elevar los niveles de desempleo. La micro, pequeña y mediana empresa existentes requieren de apoyos para su crecimiento; por esta razón se promoverá la organización de estas empresas para realizar gestiones en la obtención de 
financiamiento, capacitación, espacios, asesoría y asistencia técnica, así como la adopción de tecnologías de vanguardia (PMA, 2006).

Uno de los obstáculos para incentivar la inversión es la elevada cantidad de trámites burocráticos que se solicitan para el registro e instalación de nuevas empresas. Para evitar esta situación y facilitar la generación de empleo, este gobierno municipal promoverá la simplificación administrativa de los permisos y licencias que son de su competencia (PMA, 2006).

El comercio que opera en el municipio satisface parcialmente las necesidades de los consumidores ya que los comercios son ambulantes, en la mayoría de los casos, con días establecidos para la venta en las localidades con acceso carretero, donde se concentran para los días de plaza.

Acaxochitlán cuenta con grandes atractivos turísticos y con el potencial necesario para alcanzar los niveles más altos de desarrollo en este sector. El turismo se puede convertir en una actividad de generación de recursos en la región; por tales cualidades, y aunado a las condiciones favorables existentes, es necesario impulsar el turismo rural, turismo de aventura, turismo deportivo, deporte extremo, equitación, ciclismo, alpinismo, fotografía artística de paisaje y el ecoturismo.

El objetivo general de este eje estratégico es la creación de empresas generadoras de empleos permanentes para detonar la inversión y desarrollo de Acaxochitlán. Este eje estratégico considera cinco líneas de acción: fomento a la competitividad de pequeñas y medianas empresas, financiamiento al comercio y abasto, fomento a las exportaciones, fomento al turismo, y vinculación con instituciones de educación e investigación para el desarrollo. A continuación se mencionan éstas líneas de acción y, además, se establecen los proyectos de cada una de éstas:

FOMENTO A LA COMPETITIVIDAD DE PEQUEÑAS Y MEDIANAS EMPRESAS Financiamiento al desarrollo de las pequeńas y medianas empresas Estudio de factibilidad de parques industriales

FinanCiamiento Al COMERCiO Y ABASTO

Mejoramiento de la infraestructura en mercado municipal

Financiamiento a la comercialización de productos

FOMENTO A LAS EXPORTACIONES

Estudio de factibilidad técnico-económico para la exportación

Capacitación para la exportación

Financiamiento para la exportación

FOMENTO AL TURISMO

Estudio de factibilidad al desarrollo del ecoturismo

Impulso de la infraestructura para el desarrollo turístico 
VINCULACIÓN CON INSTITUCIONES DE EDUCACIÓN

E INVESTIGACIÓN PARA EL DESARROLLO

Realización de convenio de colaboración con instituciones públicas y privadas

Vinculación con instituciones de capacitación

\section{Disponibilidad de servicios públicos básicos de calidad}

Los servicios públicos básicos implican para las autoridades municipales, estatales y federales, un esfuerzo constante para proveer de vivienda, educación, salud, agua potable, drenaje, alcantarillado y servicio eléctrico a una mayor cobertura de la población. El incremento en la cobertura de estos servicios es una herramienta eficaz para reducir la marginación y propiciar un desarrollo más equitativo en las localidades, sobre todo en las que, por sus condiciones de dispersión y lejanía, manifiestan menores niveles de desarrollo.

En la actualidad, los esfuerzos de los gobiernos federal, estatal y municipal han sido insuficientes $y$, poco a poco, se ha dotado de los servicios básicos a las localidades que de acuerdo con la prioridad de sus peticiones se justifican.

El objetivo general de este eje estratégico es proveer de servicios públicos básicos al total de la población para elevar su nivel de vida. De acuerdo con la problemática planteada en los Talleres de planeación participativa, se proponen siete líneas de acción: vivienda digna para todos, disponibilidad de electricidad, agua potable y drenaje en todos los hogares, consolidación de la educación de calidad, suficiente transporte público, acceso a la salud de calidad y disponibilidad de panteones y plazas públicas, en buen estado, en comunidades. Estas líneas de acción, junto con sus respectivos proyectos se presentan enseguida:

VIVIENDA DIGNA PARA TODOS

Satisfacción de la demanda de vivienda

DiSPONIBILIDAD DE ELECTRICIDAD EN TODOS LOS HOGARES

Instalación de electricidad de buena calidad

Ampliación de electricidad en todos los hogares

Reparación o compra de celdas solares

DisponibilidAd DE AGUA POTABLE Y DRENAJE

Disponibilidad de agua entubada en comunidades

Disponibilidad de drenaje en comunidades Ampliación de agua potable y drenaje en la cabecera municipal 
Consolidación de LA EDUCACión de CALIDAD

\section{Creación de escuelas de educación básica en comunidades}

Otorgamiento de apoyos a estudiantes

Suficiente TRANSPORTE PÚBLICO

Trasporte público suficiente en comunidades

Modernización del transporte público

ACCESO A LA SALUD DE CALIDAD

Construcción de clínicas en comunidades

Amplia cobertura de afiliación de la población en

instituciones de salud

Suficiente personal médico, infraestructura y medicamentos

en hospitales

DisPONIBILIDAD DE PANTEONES Y PLAZAS PÚBLICAS EN BUEN ESTADO EN COMUNIDADES

Remodelación y construcción de panteones en comunidades

Remodelación y construcción de plazas públicas en comunidades

\section{Honestidad y eficiencia en la asignación de recursos a la sociedad}

La sociedad de Acaxochitlán exige honestidad en el manejo de los recursos públicos, en la eficiencia de los procesos administrativos, en la rendición de cuentas con claridad y oportunidad, y demanda servidores públicos comprometidos en atender a la población. Los habitantes desean que se hable con la verdad, plantear sus inquietudes y necesidades, y que éstas sean atendidas de manera responsable.

Es obligación del Ayuntamiento planear y organizar los programas y acciones que atiendan a los intereses de la comunidad; también le corresponde proporcionar a la población la información necesaria sobre las diferentes actividades del gobierno municipal, el avance de las obras públicas que realiza, así como la referencia de quienes ocupan cargos en el Ayuntamiento. Para hacer posible esta responsabilidad es elemental mejorar y transparentar la relación entre gobierno y sociedad, con el fin de erradicar la corrupción, la ineficiencia, la impunidad, el abuso y la irresponsabilidad; es decir, se deben ampliar los espacios de comunicación y participación ciudadana para asegurar que en el gobierno de Acaxochitlán existan instrumentos y mecanismos eficaces para la medición, seguimiento y evaluación de resultados, difundir la información del gobierno municipal de carácter público y garantizar a la ciudadanía el acceso a ella, impulsar el desempeño honesto de los servidores públicos y promover una efectiva rendición de cuentas (PMA, 2006).

El objetivo general de este eje estratégico es tener funcionarios públicos que trabajen responsablemente por el bienestar del municipio de 
Acaxochitlán. Así, el presente eje estratégico implica llevar a cabo cuatro líneas de acción: acceso a la información en la asignación de recursos públicos del municipio, atención a la ciudadanía de manera cordial y ágil, eficiencia en la entrega de recursos públicos a la población, y focalización eficiente de la población beneficiada. Enseguida se presentan estas líneas de acción con sus respectivos proyectos:

ACCESO A LA INFORMACIÓN EN LA ASIGNACIÓN DE RECURSOS PÚBLICOS DEL MUNICIPIO

\section{Fomento a la transparencia y honestidad}

Capacitación al personal de la administración pública municipal ATENCIÓN A LA CIUDADANÍA DE MANERA CORDIAL Y ÁGIL

\section{Colocación de módulos de atención al público}

EFICIENCIA EN LA ENTREGA DE RECURSOS PÚBLICOS A LA POBLACIÓN Entrega de recursos a la población beneficiada a tiempo

FOCALIZACIÓN EFICIENTE DE LA POBLACIÓN BENEFICIADA

Aumento en la cobertura de la población que necesita apoyos públicos municipales

Estudio de focalización de la población objetivo en la implementación de programas sociales

\section{Provisión de apoyos a grupos vulnerables}

Atendiendo a la transición demográfica, los adultos mayores se han convertido en la población más vulnerable, ya que por falta de previsión y cultura no se anticipan los problemas de salud como la pérdida normal de la audición, visión y memoria, la presencia del cáncer y de las enfermedades crónico degenerativas, entre ellas, la diabetes, hipertensión arterial, artritis y osteoporosis. Ante este escenario es necesario fortalecer las condiciones generales del entorno social para favorecer la integración plena de los adultos mayores, ya que su experiencia y sabiduría es un capital que se debe aprovechar al máximo; para lograrlo, se deben implementar programas de atención integral a los adultos mayores, fortalecer la inversión y a las instituciones de apoyo a este sector, así como garantizar su acceso generalizado a los servicios de salud, protección jurídica y seguridad social en un entorno de respeto y dignidad.

La mujer en el municipio ha luchado por los derechos que las leyes de nuestro país le otorgan, demostrando que tiene la capacidad para poder desempeñarse en cualquier actividad productiva, social y política. La participación que actualmente tienen las mujeres no ha sido espontánea ni mucho menos fácil, por el contrario, ha sido parte de un largo proce- 
so histórico y social lleno de contratiempos, limitaciones, discriminaciones, críticas, obstáculos, sin sabores, malos tratos, bajos salarios, etc.

En el municipio la mujer ocupa un lugar preponderante, ya que de ella depende, en gran parte, el desarrollo de todos los ámbitos. Para desarrollar el pleno potencial de las mujeres se necesita contar con las condiciones favorables dentro de su entorno comunitario y familiar, así como proveer de espacios propicios para su participación en la vida política, económica, social y cultural del municipio. Para avanzar en esta tarea se requiere identificar los problemas que aquejan a las mujeres, entre ellos: el acceso desigual a los servicios de salud y educación, oportunidades laborales y de espacios en la toma de decisiones, madres solteras, el creciente impacto de la pobreza en la población femenina, así como la violencia intrafamiliar. El gobierno municipal debe fomentar una cultura entre la población para dar un trato más digno a la mujer, así como impulsar su participación en actividades productivas y ofrecerles igualdad de oportunidades.

Los individuos con capacidades diferentes que viven en el municipio de Acaxochitlán se enfrentan a serios problemas relacionados con el cuidado de su salud y alimentación debido a la carencia de recursos, por lo que es necesario implementar programas sociales de apoyo a discapacitados que incidan directamente en un mejoramiento en su nivel de vida.

La migración en Acaxochitlán es cada vez más acentuada, integrantes de familias deciden salir de sus comunidades en busca de oportunidades de empleo, ocasionando disminución del ingreso (al principio), desintegración familiar y, sobre todo, pérdida de capital humano; por lo anterior, es de suma importancia generar fuentes de empleos en la región para evitar la migración masiva de los núcleos familiares.

Las comunidades y pueblos indígenas del país enfrentan condiciones de desigualdad, pobreza extrema y alta marginalidad, producto de diversos factores como la descapitalización de las actividades agropecuarias, la falta de inversión productiva, su nulo acceso al sistema financiero, la escasa posibilidad de dar valor agregado a sus productos y los problemas de certeza jurídica relacionados con la propiedad individual y la tenencia de la tierra; dado lo anterior, la población indígena de Acaxochitlán requiere oportunidad de empleos y disponibilidad de servicios en condiciones de igualdad y justicia.

La finalidad de este eje estratégico es fomentar el bienestar de los grupos vulnerables en un ambiente de servicio con equidad. Este eje consta de cinco líneas de acción: otorgar apoyos a adultos mayores, estímulos económicos para madres solteras, apoyos a discapacitados, desarrollo de grupos indígenas y apoyos a migrantes. Enseguida se presentan las líneas de acción con sus proyectos 
Otorgamiento de Apoyos a ADUltos mayores

Atención médica pública de calidad para adultos mayores

Diseño y construcción de lugares recreativos para adultos mayores Apoyo monetario a adultos mayores

EsTÍMULOS ECONÓMICOS A MADRES SOLTERAS

Apoyo monetario a madres solteras para mantener a su familia

Otorgamiento de apoyos a discapacitados

Cuidado de la salud de los discapacitados

Provisión de sillas de ruedas a discapacitados

Apoyo monetario a familiares de discapacitados

DESARROLlo DE PROGRAMAS PARA BENEFICIO DE LOS GRUPOS INDÍGENAS

Proveer los servicios públicos básicos a grupos indígenas

Generación de oportunidades de desarrollo a grupos indígenas Apoyos a migrantes

\section{Apoyo a la familia del migrante}

También en la quinta sesión del zopp se realizó el Análisis de involucrados, donde se describen las funciones, interés, fortalezas y debilidades de los participantes en los talleres (anexo 1). En esta sesión y en el último taller zopp, realizado el 14 de noviembre de 2008, al que asistieron 37 personas, se elaboraron la MPP y la Planeación operativa del proyecto. Como ejemplo, el anexo 2 presenta la MPp del eje estratégico 1. La Planeación operativa del proyecto, del eje estratégico 1 , se presenta en el anexo 3, que muestra el primer proyecto con su actividad y sus subactividades. Los resultados de este estudio se muestran en los ejes estratégicos antes presentados.

\section{Conclusiones}

El zopp representa una herramienta metodológica indispensable en la identificación y solución de problemas a nivel local. La identificación de necesidades comunes en un sistema participativo, representa un diagnóstico real de los obstáculos que truncan el desarrollo regional; de manera que, atender con responsabilidad estos problemas propicia un mayor bienestar social y económico de dicha población, además de generar y consolidar el tejido social, necesario para el fortalecimiento de un sistema institucional local que actualmente se encuentra deteriorado. Esta investigación implicó el apoyo activo de las autoridades municipales de Acaxochitlán y de la Universidad Autónoma del Estado de Hidalgo, así como la participación responsable de la población de Acaxochitlán, delegados municipales, comisariados ejidales, representantes de colonias, represen- 
tantes de productores agrícolas y pecuarios, empresarios, líderes políticos y sociales; asimismo, la moderación externa especializada fue fundamental para la elaboración del presente Plan de Desarrollo Económico y Social de Acaxochitlán, 2009-2015.

Para tener resultados favorables, el zopp establece la necesidad de llevar a cabo las diferentes actividades que se plantean considerando circunstancias cambiantes, es decir, el responsable de llevar a cabo las diferentes acciones debe tener la capacidad de enfrentar las nuevas situaciones que se presenten, modificando, incluso, las acciones predeterminadas. El problema central identificado por los diferentes participantes en los talleres zopp, realizados en el municipio de Acaxochitlán, fue el desempleo y falta de servicios públicos básicos; para la solución de esta problemática se determinaron siete ejes estratégicos: fortaleza institucional, competitividad y desarrollo de la actividad primaria, infraestructura carretera y de servicios adecuados, empresas generadoras de empleos permanentes, disponibilidad de servicios públicos básicos de calidad, honestidad y eficiencia en la asignación de recursos a la sociedad, y provisión de apoyos a grupos vulnerables.

Este plan de desarrollo municipal es integral y de largo plazo, puesto que considera los diferentes aspectos de desarrollo económico y social del municipio de Acaxochitlán con visión tanto en el presente como en el futuro; para el cumplimiento de sus objetivos es indispensable llevar a cabo los diferentes proyectos con sus actividades y con la participación responsable de los involucrados.

Finalmente, el zopp es aplicable a todo tipo de proyectos, independientemente de si la organización contraparte es un organismo estatal, un banco, una asociación u otra organización no gubernamental, y de si el grupo destinatario está constituido por los habitantes de un poblado o por empresas del sector privado. La experiencia demuestra que los proyectos sólo tienen éxito cuando se basan en el esfuerzo de los grupos destinatarios. 


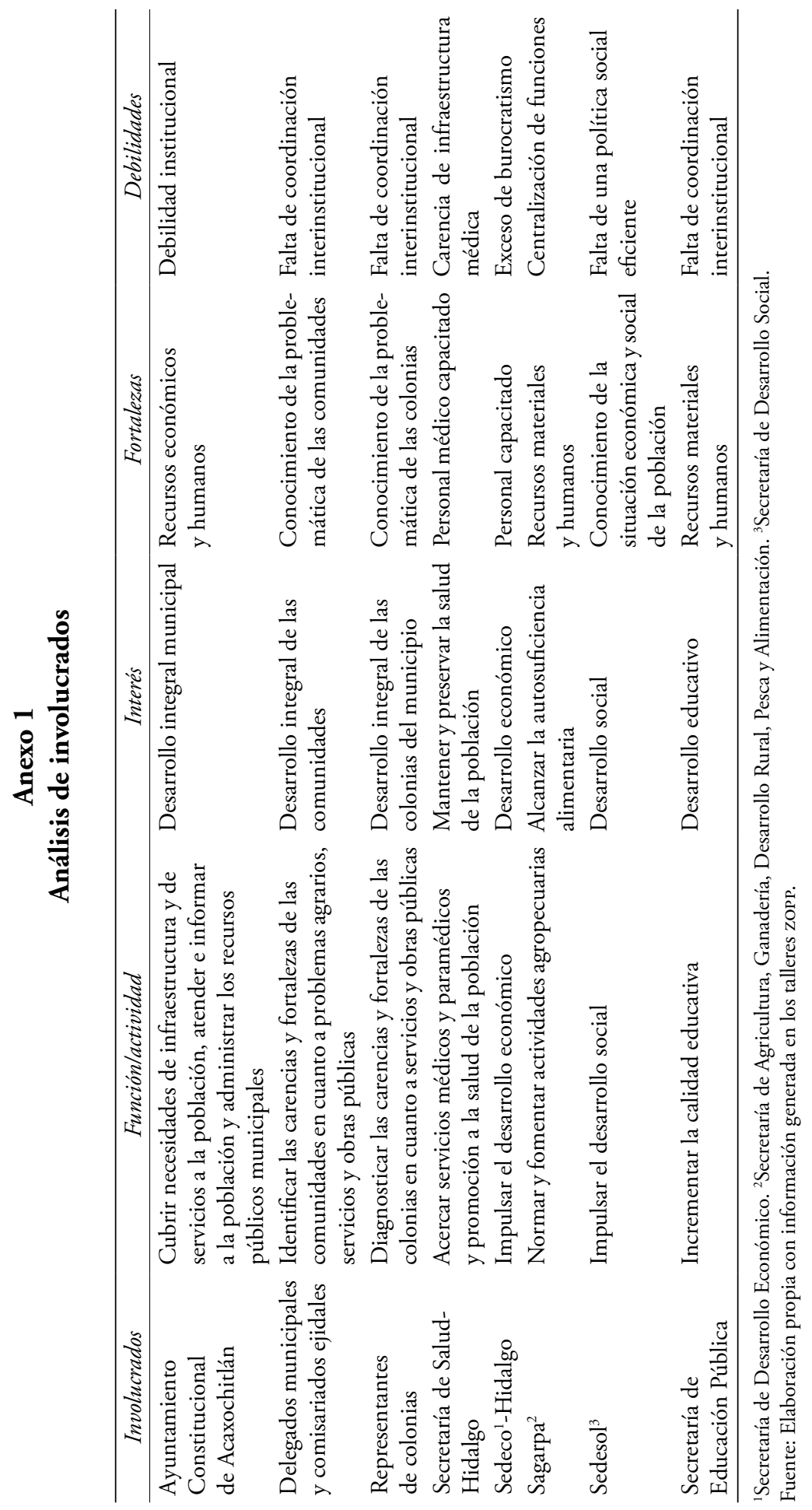




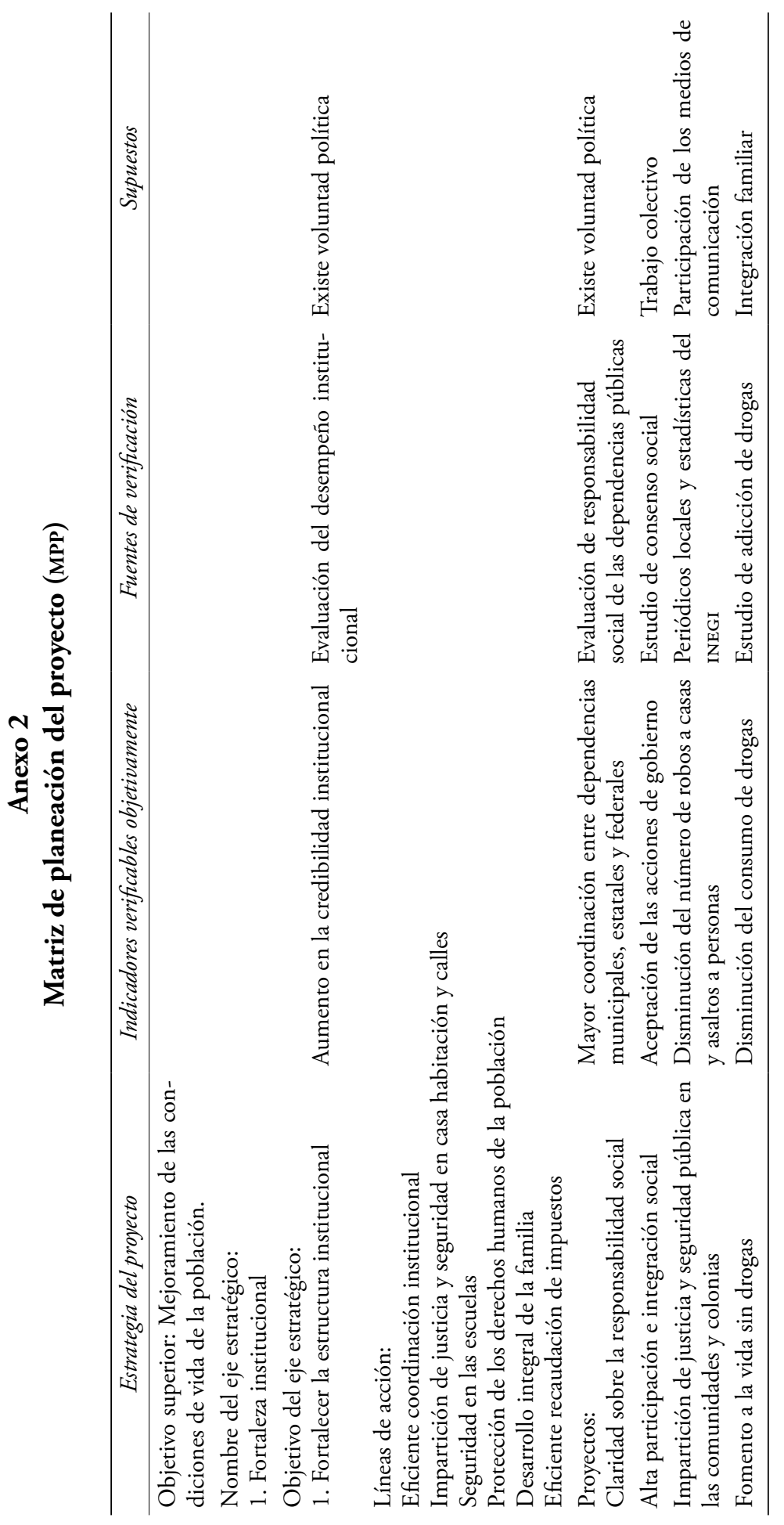




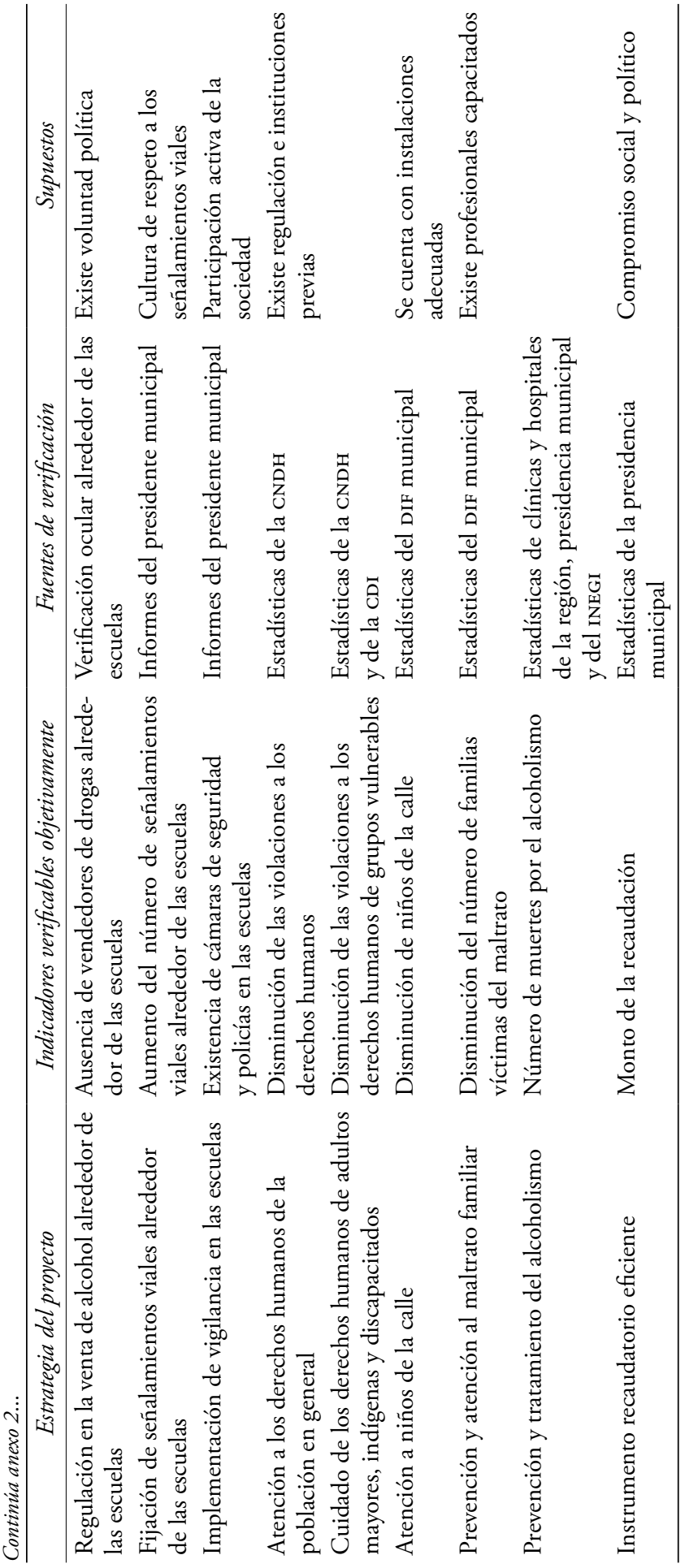




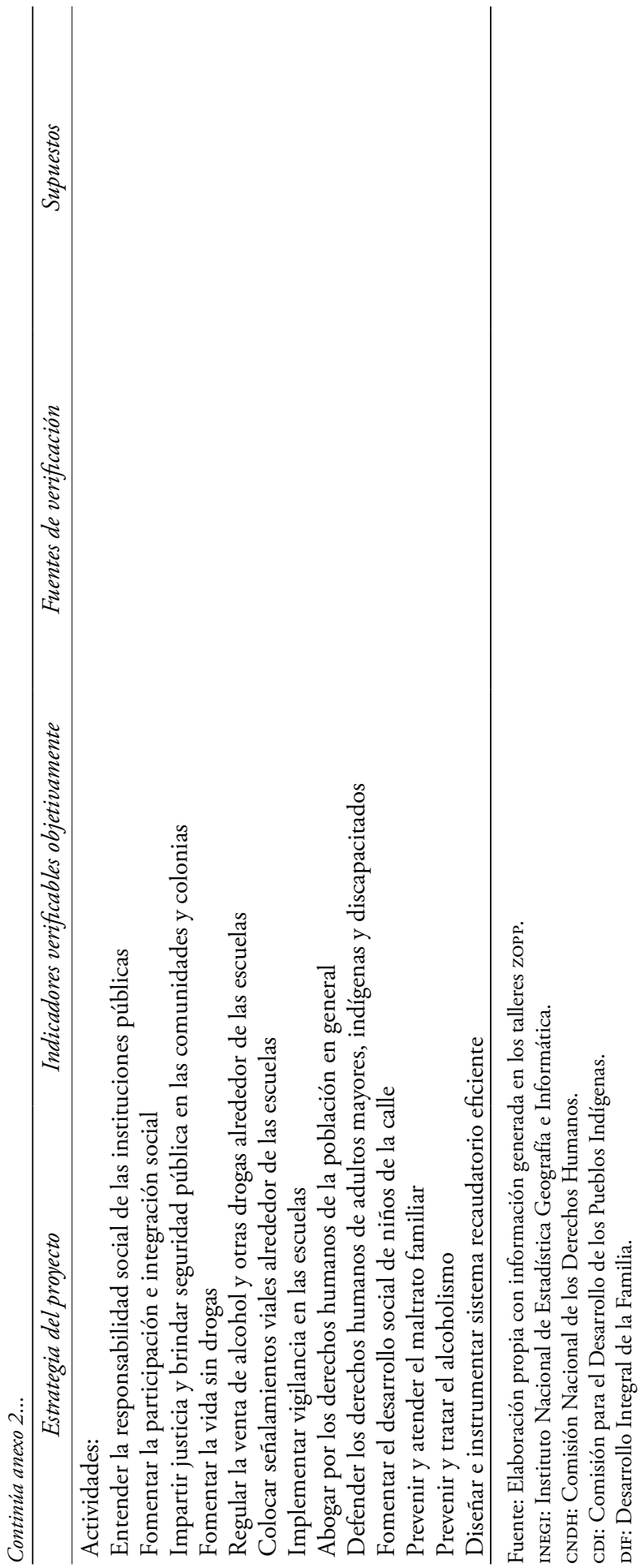




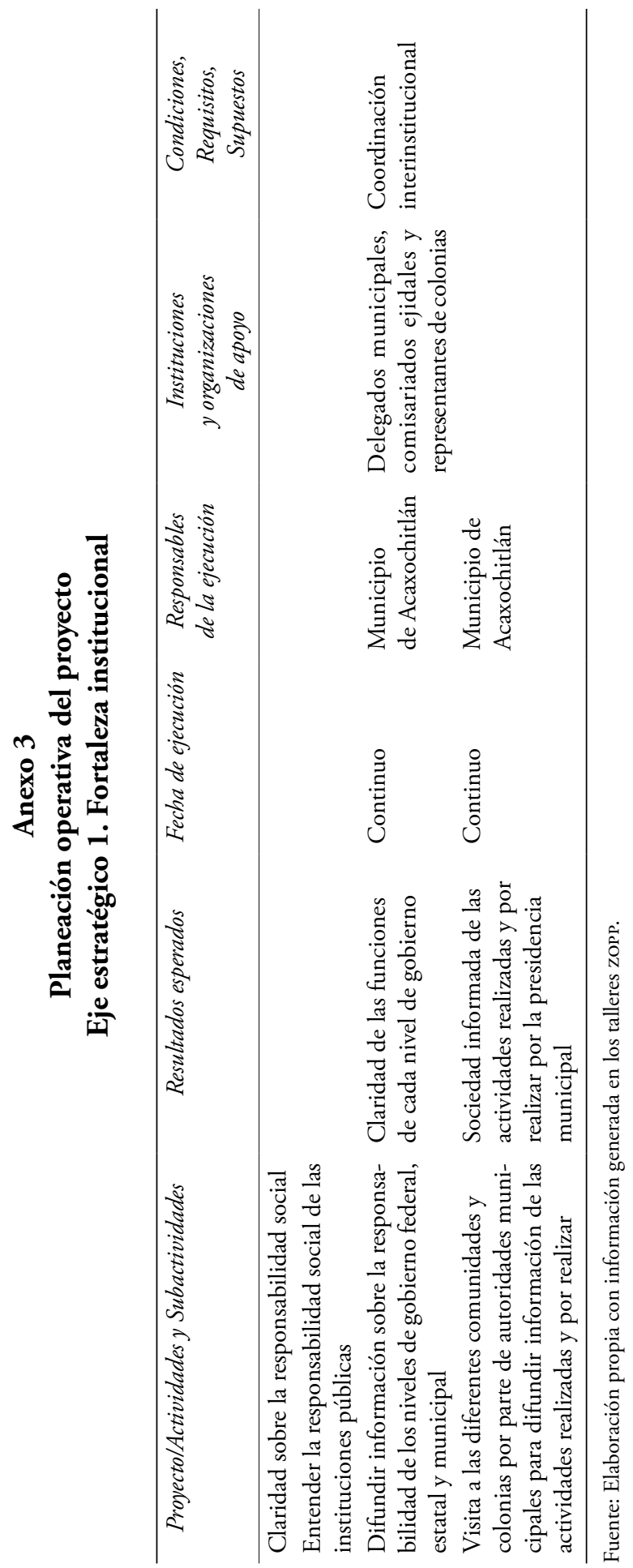




\section{Bibliografía}

вм (Banco Mundial) (1997), El Estado en un mundo en transformación. Informe sobre desarrollo mundial, Oxford University, Oxford.

Blakely, Edward y Nancey Green Leigh (2010), Planning local economic development: theory and practice, SAGE Publications, Inc., Thousand Oaks, California.

Canabal-Cristiani, Beatriz (2001), Los caminos de la montaña. Formas de reproducción social en la montaña de Guerrero, UAM-X-CIESASMiguel Ángel Porrúa, México.

Cepal (Comisión Económica para América Latina y el Caribe) (2002), Globalization and Development, Naciones Unidas, Nueva York.

Conturruero-Menta, Romero (1998), Planificación y gestión estratégica del desarrollo local, Cuadernos de Aguilar: textos de apoyo, España.

Constitución Política de los Estados Unidos Mexicanos (2002), Leyes y códigos de México, Miguel Ángel Porrúa, México.

FAO (Food and Agriculture Organization of the United Nations) (1990), The community toolbox. The idea, methods and tools for participatory assessment, monitorring and evaluation in community forestry, Community Forestry Field Manual 2, Rome.

Farrington, John y Adrienne M. Martin (1988), Farmer participation in agricultural research: a review of concepts and practices, Overseas Development Institute, London.

Forster, Reiner y Juliane Osterhaus (1995), Marco orientativo para la ejecución de proyectos, Cooperación Técnica Alemana, México.

GEH (Gobierno del Estado de Hidalgo) (2005), Plan Estatal de Desarrollo 2005-2011, Pachuca, Hidalgo.

Geilfus, Frans (2002), 80 herramientas para el desarrollo participativo: diagnóstico, planificación, monitoreo, evaluación, IICA, México.

Giménez, Gilberto (1994), “Comunidades primordiales y modernización en México”, en Gilberto Giménez y Ricardo Pozas (coords.), 
Modernización e identidades sociales, UnAM-Instituto Francés de América Latina, México, pp. 152-166.

Giménez, Gilberto (1996), “Territorio y cultura”, Estudios sobre culturas contemporáneas, II (4), Universidad de Colima, Colima, pp. 28-43.

gTz (Agencia Alemana de Cooperación Técnica: Team Technologies) (1995), Marco orientativo para la ejecución de proyectos de la Cooperación Técnica Alemana a través de la GTZ, GTZ, México.

INEGI (Instituto Nacional de Estadística y Geografía) (2000a), Marco geoestadistico: Conjunto de datos vectoriales de la carta topográfica, 1:50 000, Instituto Nacional de Estadística y Geografía, México.

INEGI (Instituto Nacional de Estadística y Geografía) (2000b), Censo de Población y Vivienda 2000, Instituto Nacional de Estadística y Geografía, México.

INEGI (Instituto Nacional de Estadística y Geografía) (2010), “Censo de Población y Vivienda", Instituto Nacional de Estadística y Geografía, México, <http://www.censo2010.org.mx/>, 13 de abril de 2011.

Iriarte, Alicia, Mariana Vázquez y Claudia Bernazza (2003), "Democracia y ciudadanía: reflexiones sobre la democracia y los procesos de democratización en América Latina", Futuros, 1 (4), pp. 36-48, $<$ http://www.revistafuturos.info/futuros_4/democra_ciuda_1. htm>, 26 de junio de 2010.

Leurs, Robert (1996), "Current challenges facing participatory rural appraisail", Public administration and development, 16, John Wiley and Sons, Ltd., pp. 57-72.

Morales, Federico (1998), Desarrollo local: principios, metodologías y experiencias, CESEM-Fundación Friedich Ebert Stiftung, México.

Musgrave, Richard (1993), Hacienda pública, teoría y aplicaciones, McGrawHill, México.

Olvera-Rivera, Alberto (1999), "Los modos de la recuperación contemporánea de la idea de sociedad civil”, en Alberto Olvera (coord.), 
La sociedad civil: de la teoría a la realidad, El Colegio de México, México, pp. 27-53.

Osorio-Martínez, Elena (2009), "La participación ciudadana en asociaciones civiles y la democratización de la sociedad: dos casos oaxaqueños”, en Julia del Carmen Chávez- Carapia y Martín Castro Guzmán (coords.), Cultura de participación y construcción de ciudadanía, Miguel Ángel Porrúa, México, pp. 167-185.

Osterhaus, Juliane y Walter Salzer (1995), Diferenciación según género en el ciclo del proyecto. Indicaciones para la planificación, monitoreo y evaluación, GTZ, México.

Pardo, María del Carmen (1994), "La gestión municipal, ¿̨motor o freno para el ejercicio democrático?”, en Mauricio Merino (coord.), En busca de la democracia municipal. La participación ciudadana en el gobierno local mexicano, El Colegio de México, México, pp. 253-282.

Pérez-Ledesma, Manuel (comp.) (2000), Ciudadanía y democracia, Editorial Pablo Iglesias, Madrid.

PMA (Presidencia Municipal de Acaxochitlán) (2006), Plan de Desarrollo Municipal de Acaxochitlán, 2006-2009, PMA, Acaxochitlán, Hidalgo.

PNUD (Programa de las Naciones Unidas para el Desarrollo) (2004), $\mathrm{La}$ democracia en América Latina. Hacia una democratización de ciudadanas y ciudadanos, http:/www.pnud.com, 15 de enero de 2011.

Ramírez-García, Adán Guillermo (2004), Guía metodológica para la formulación y evaluación de proyectos de educación ambiental bajo un enfoque participativo, Centro Regional Universitario del NoresteUniversidad Autónoma Chapingo, Estado de México.

Sánchez-Bernal, Antonio, Édgar Tovar García y Antonia Sánchez Martínez (2003), "Evaluación del desempeño de los gobiernos municipales de Jalisco. Hacia una política regional de fortalecimiento municipal", Gestión Municipal, año 1, 1, Universidad de Guadalajara, Jalisco, pp. 55-72. 
Schönhuth, Michael (1994), Participatory learning approaches: rapid rural appraisal, participatory appraisal, Cooperación Técnica Alemana, GTZ, Rossdorf.

Silva-Lira, Iván (2003), Metodología para la elaboración de estrategias de desarrollo local, CEPAL-ILPES, Chile.

Tello, Carlos (2007), Estado y desarrollo económico: México 1920-2006, Facultad de Economía, unam, México.

Terrones-Cordero, Aníbal y Yolanda Sánchez Torres (2010), Planeación participativa: Teoría y práctica, Plaza y Valdés-UAEH, México.

\section{Talleres ZOPP}

Taller zopp 1. Realizado el 27 de octubre de 2008 de 08:00 a 14:00 horas en el auditorio de la presidencia municipal de Acaxochitlán. Asistieron 36 personas.

Taller zopp 2. Realizado el 29 de octubre de 2008 de 08:00 a 14:00 horas en el auditorio de la presidencia municipal de Acaxochitlán. Asistieron 37 personas.

Taller zopp 3. Realizado el 31 de octubre de 2008 de 08:00 a 14:00 horas en el auditorio de la presidencia municipal de Acaxochitlán. Asistieron 36 personas.

Taller zopp 4. Realizado el 10 de noviembre de 2008 de 08:00 a 14:00 horas en el auditorio de la presidencia municipal de Acaxochitlán. Asistieron 37 personas.

Taller zopp 5. Realizado el 12 de noviembre de 2008 de 08:00 a 14:00 horas en el auditorio de la presidencia municipal de Acaxochitlán. Asistieron 37 personas.

Taller zopp 6. Realizado el 14 de noviembre de 2008 de 08:00 a 14:00 horas en el auditorio de la presidencia municipal de Acaxochitlán. Asistieron 37 personas. 
Recibido: 5 de mayo de 2011. Reeenvidado: 12 de septiembre 2011. Aceptado: 5 de octubre 2011.

Aníbal Terrones Cordero. Es doctor en ciencias por el Colegio de Postgraduados, maestro en economía del desarrollo rural e ingeniero agrónomo, especialista en economía agrícola por la Universidad Autónoma Chapingo. Actualmente es profesor-investigador de la licenciatura en Economía en la Universidad Autónoma del Estado de Hidalgo. Es miembro del Sistema Nacional de Investigadores, nivel I. Su línea de investigación actual es modelos económicos, innovación y estrategias de desarrollo. Entre sus publicaciones recientes destacan: "Demanda de insumos de la producción agrícola en México, 1975-2011”, Universidad y Ciencia, Universidad Juárez Autónoma de Tabasco, Villahermosa, pp. 81-91 (2010); "Crecimiento económico y exportaciones en México, 1970-2009. Un análisis sexenal”, Expresión Económica. Revista de Análisis 24, Universidad de Guadalajara, Guadalajara, pp. 77-88 (2010); Planeación Participativa: Teoría y Práctica, Plaza y Valdés-Universidad Autónoma del Estado de Hidalgo, México (2010); Globalización, Crisis y Crecimiento en México, Plaza y Valdés-Universidad Autónoma del Estado de Hidalgo, México (2011); Tópicos de Economía Ecológica y Desarrollo Regional, Universidad Autónoma del Estado de Hidalgo, Pachuca (2011). 